www.jmscr.igmpublication.org

Impact Factor 5.84

Index Copernicus Value: 71.58

ISSN (e)-2347-176x ISSN (p) 2455-0450

crossref DOI: _https://dx.doi.org/10.18535/jmscr/v5i11.116

Journal Of Medical Science And Clinical Research

IGM Publication

An Official Publication of IGM Publication

\title{
Dexmedetomidine as an Adjuvant with Ropivacaine in Supraclavicular Brachial Plexus Block in Upper Limb Surgeries: A Case Control Study
}

\author{
Authors \\ Dr Sonam Sushilkumar Gupta ${ }^{1}$, Dr Jayant Prakashrao Shinde ${ }^{2}$ \\ ${ }^{1,2}$ Senior Resident, Department of Anesthesiology, Dr Shankarrao Chavan Government Medical College, \\ Nanded (MS)- India \\ Corresponding Author
}

Dr Jayant Prakashrao Shinde

Senior Resident, Department of Anesthesiology, Dr Shankarrao Chavan Government Medical College,

Nanded (MS)- India

\begin{abstract}
Background and Aims: The aim of this study was to find out the effect of Dexmedetomidine used as an adjuvant with Ropivacaine in Supraclavicular brachial plexus block in upper limb surgeries.

Materials and Methods: 80 patients undergoing elective upper limb surgeries under Supraclavicular brachial plexus block and belonging to American society of Anesthesiologists Grade I or II were divided into 2 groups of 40 patients each. Group A $(n=40)$ received $30 \mathrm{ml} 0.5 \%$ Ropivacaine and $1 \mathrm{ml}$ normal saline and Group $D(n=40)$ received $30 \mathrm{ml} 0.5 \%$ Ropivacaine and $1 \mu \mathrm{g} / \mathrm{kg}$ of Dexmedetomidine. The primary outcome was evaluated in term of duration of analgesia. Other outcomes which were evaluated included time of onset and duration of sensory and motor blockade, degree of analgesia and sedation, vital parameters during and in immediate postoperative period.

Results: Demographic profile and mean duration of surgery was similar in both the groups. Onset of sensory and motor blockade was found to be earlier in Group D than in Group A. The duration of sensory and motor block was statistically significantly prolonged in group D than in group A. Duration of analgesia and degree of sedation was also higher in group D than in group A. The incidence of bradycardia was more in group D than in Group A. Other vital parameters like mean arterial pressure and SPO2 were comparable in both the groups.

Conclusion: Addition of dexmedetomidine as an adjuvant to ropivacaine in supraclavicular brachial Plexus block in upper limb surgeries is associated with prolonged postoperative analgesia, better sedation and shortened time for onset of sensory and motor block. It is associated with statistically significant prolonged duration of brachial plexus block in comparison with use of ropivacaine alone. Use of dexmedetomidine is found to be associated with increased incidence of bradycardia.

Keywords: Dexmedetomidine, Ropivacaine, Supraclavicular brachial plexus block, Bradycardia, Analgesia and Sedation.
\end{abstract}

\section{Introduction}

Anesthesiologists have been using upper extremity peripheral nerve blocks since decades. It is used as a sole method of anesthesia or as a supplement to general anesthesia in upper limb surgeries $^{[1]}$. Its use is associated with prolonged 
postoperative analgesia and reduced need for opioid analgesics in perioperative period. With the use of ultrasound various blocks like interscalene block, supra and infraclavicular and brachial plexus blocks are being more efficiently and frequently performed ${ }^{[2]}$. Many Cochrane based systematic reviews have supported use of ultrasound guided blocks and its effectiveness in limb surgeries. These reviews have concluded that there is a high level of evidence supporting ultrasound guided regional blocks for better postoperative analgesia. These blocks are associated with better pain control, reduced incidence of complications and early recovery ${ }^{[3]}$.

One of the drawbacks of using peripheral nerve block is the possibility of resolution of block before the period of severe postoperative pain. Increasing the volume of local anesthetic (LA) drug is one of the ways by which this possibility is averted but increase dose of LA may be associated with systemic side effects ${ }^{[4]}$. Alternatively various adjuvants to local anesthetics such as opioids, neostigmine and tramadol etc have been tried to increase the duration of nerve block and duration of postoperative analgesia ${ }^{[5]}$. Dexmedetomidine is an alpha2 adrenoreceptor agonist which is currently gaining popularity for its sedative and analgesic properties. Many researchers have reported that Dexmedetomidine when used as an adjuvant with other local anesthetics in regional blocks is associated with prolonged block and better postoperative analgesia ${ }^{[6]}$.

The studies commonly involved use of Dexmedetomidine with bupivacaine or levobupivacaine. Ropivacaine is similar to bupivacaine in its properties but have lesser side effects in comparison with bupivacaine. Ropivacaine is frequently used for peripheral nerve blocks because of its property to produce quick, dense and prolonged block ${ }^{[7]}$. Moreover it has also got a better safety profile than bupivacaine. The basic mechanism of action of Ropivacaine is reversible inhibition of sodium influx in nerve cells ${ }^{[8]}$. It is less lipophilic and hence less likely to enter large myelinated motor fibers causing difficulties in motor blockade. Moreover this property is also responsible for motor sensory differentiation wherein sensory blockade is more predominant and this property can be exploited in surgeries where motor blockade is undesirable ${ }^{[9]}$.

Despite the fact that Ropivacaine has got a better safety profile than bupivacaine there are very limited studies which have dealt with the aspect of use of Dexmedetomidine as an adjuvant with Ropivacaine in various regional blocks. For this reason and with this background in mind we undertook this study to assess the effect of Dexmedetomidine used as an adjuvant with Ropivacaine in Supraclavicular brachial plexus block in upper limb surgeries. In this case control study we evaluated duration of analgesia as the primary outcome. Other parameters which were studied during the course of this study were time of onset and duration of sensory and motor blockade, degree of sedation and hemodynamic stability.

\section{Materials and Methods}

This was a double blind case control study done at a tertiary care hospital situated in an urban area. Study was undertaken after approval of institutional ethical committee. 80 patients of either sex undergoing elective upper limb surgeries under Supraclavicular brachial plexus block and belonging to American society of Anesthesiologists Grade I or II were included in this study. Informed consent was taken from all the participants. Since patients included in this study were undergoing elective surgeries a preanesthetic assessment of all the patients was done 1 day prior to surgery. All patients received antacid (ranitidine) and antiemetic (ondansetron) prior to surgery. On preceding night anxiolytics like alprazolam was given to selected anxious patients only. The patients undergoing peripheral nerve blocks were explained about the procedure. Monitoring devices like ECG leads, SPO2 saturation probe and BP cuff was attached. The patient was kept in supine position and a roll was 
kept under the shoulder for neck extension. The head was turned to opposite side and the brachial plexus block was given by subclavian perivascular approach. The patients were randomized and divided into 2 groups. Group A patients received $30 \mathrm{ml}$ of $0.5 \%$ Ropivacaine and $1 \mathrm{ml}$ saline while Group D patients received $30 \quad \mathrm{ml} \quad 0.5 \%$ Ropivacaine and $1 \mu \mathrm{g} / \mathrm{kg}$ of Dexmedetomidine. IV canula was placed on the unaffected limb. Block was considered to be adequate when at least 2 nerve (ulnar, median, radial and musculocutaneous) territories were sensory as well as motor blocked. Onset of sensory time, motor blockade, level of sedation and analgesic effects were evaluated in both the groups. Heart rate, Blood pressure and Spo 2 were noted every 5 minutes for first 30 minutes and then every 15 minutes till 1 hour postoperatively.

The results were studied using various statistical methods. $\mathrm{P}<0.05$ was taken as statistically significant. Data analysis was carried out SPSS 16.0 version software. Microsoft word and excel were used for generating charts and graphs

\section{Inclusion Criteria}

- Patients undergoing elective upper limb surgeries under supraclavicular brachial plexus block.

- Age in between 18- 70 years.

- ASA Grades I and II.

\section{Exclusion Criteria}

- Patients undergoing emergency surgeries.

- ASA grade III or higher.

- Age less than 18 or more than 70 years.

- Those who refused consent.

- Patients having comorbid conditions like arrhythmias, Altered sensorium, pregnant and nursing women and patients on antipsychotics.

\section{Results}

This was a prospective double blind case control study. 80 patients undergoing elective upper limb surgeries under Supraclavicular brachial plexus block and belonging to ASA I or II were included in this study if they met the inclusion criteria.
Patient having any exclusion criteria were excluded from the study. Initially 90 patients were included in this study. Out of these 90 patients 10 patients met exclusion criteria and hence were excluded from the study. Remaining patients were divided into 2 groups Group A (30 ml of $0.5 \%$ Ropivacaine and $1 \mathrm{ml}$ saline) and Group D (30 ml $0.5 \% \quad$ Ropivacaine and $1 \mu \mathrm{g} / \mathrm{kg}$ of Dexmedetomidine).

\section{Demographic Data}

Out of the studied 80 cases Group A had a mean age of 34.60 and Group D had a mean age of 32.70 years. In group A $40 \%$ patients belonged to ASA I and $60 \%$ patients belonged to ASA II while in group D $65 \%$ and $35 \%$ patients belonged to ASA I and II respectively [Table 1].

Table 1: Demographic Data of the studied cases

\begin{tabular}{|l|c|c|}
\hline Parameters & Group A & Group D \\
\hline No of Cases & 40 & 40 \\
\hline Mean Age & $34.60 \mathrm{yrs}$ & $32.70 \mathrm{yrs}$ \\
\hline ASA & & \\
I & $16(40 \%)$ & $26(65 \%)$ \\
II & $24(60 \%)$ & $14(35 \%)$ \\
\hline
\end{tabular}

The study of mean duration of the surgery showed that it was $82+/-16.42$ minutes in group $\mathrm{A}$ and $76+/-14.32$ minutes in group D. The test of significance was applied and $\mathrm{P}$ value was found to be "Not significant" [Table 2].

Table 2 : Mean Duration of the surgery in both the groups.

\begin{tabular}{|l|c|}
\hline $\mathbf{N}=\mathbf{4 0}$ & $\mathbf{N}=\mathbf{4 0}$ \\
\hline Group A & $82+/-16.42$ minutes \\
\hline Group D & $76+/-14.32$ minutes \\
\hline P value & Not significant \\
\hline
\end{tabular}

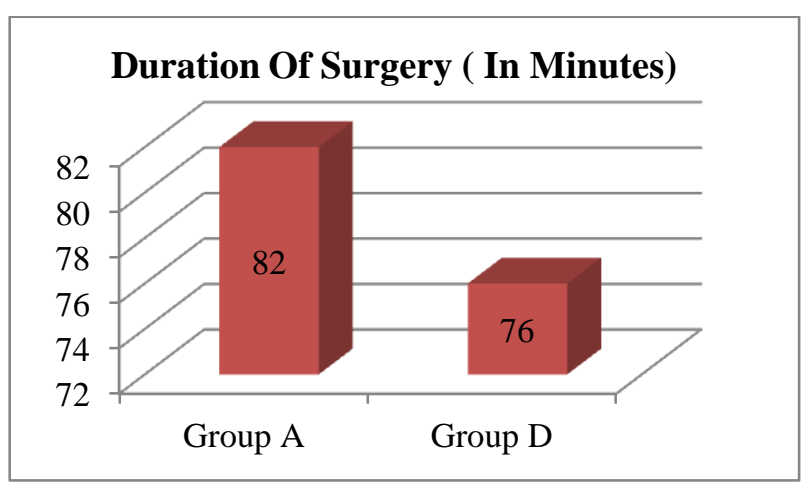

Figure 1: Mean Duration of surgery (In Minutes) in studied cases. 


\section{JMSCR Vol||05||Issue||11||Page 30494-30501||November}

The study of the mean time required for the onset of sensory blockade revealed that it was faster in group D in comparison with Group A. The mean time for onset of sensory blockade was found to be $21.30+/-8.24$ in Group A while it was in 10.12 $+/-4.02$ Group D. The difference was found to be statistically significant $(\mathrm{P}<0.001)$.

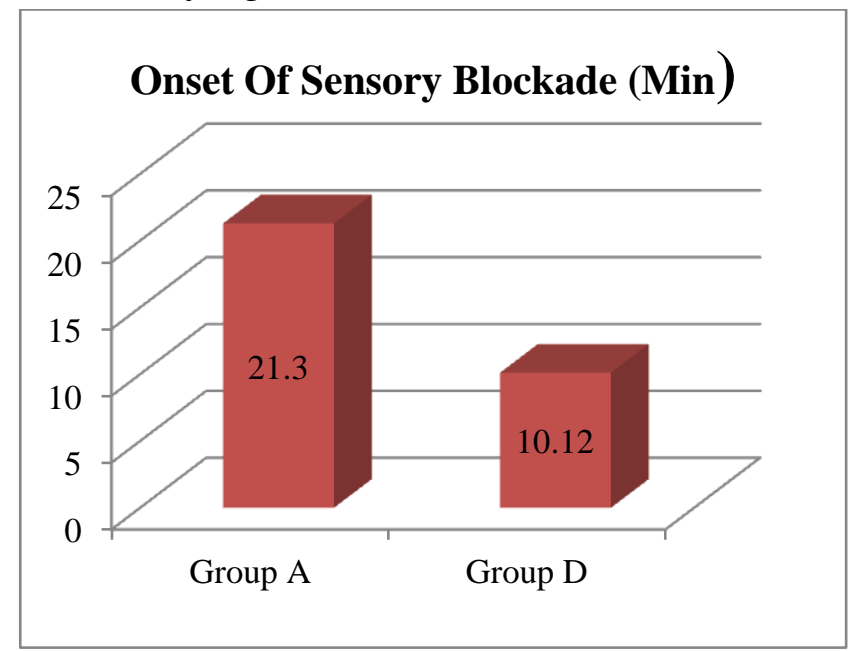

Figure 2: Onset of Sensory Blockade (In Minutes) in studied cases.

The study of the mean time required for the onset of motor blockade revealed that it was faster in group D in comparison with Group A. The mean time for onset of motor blockade was found to be $38.62+/-14.28$ in Group A while it was in 19.24 $+/-5.86$ Group D. The difference was found to be statistically significant $(\mathrm{P}<0.001)$.

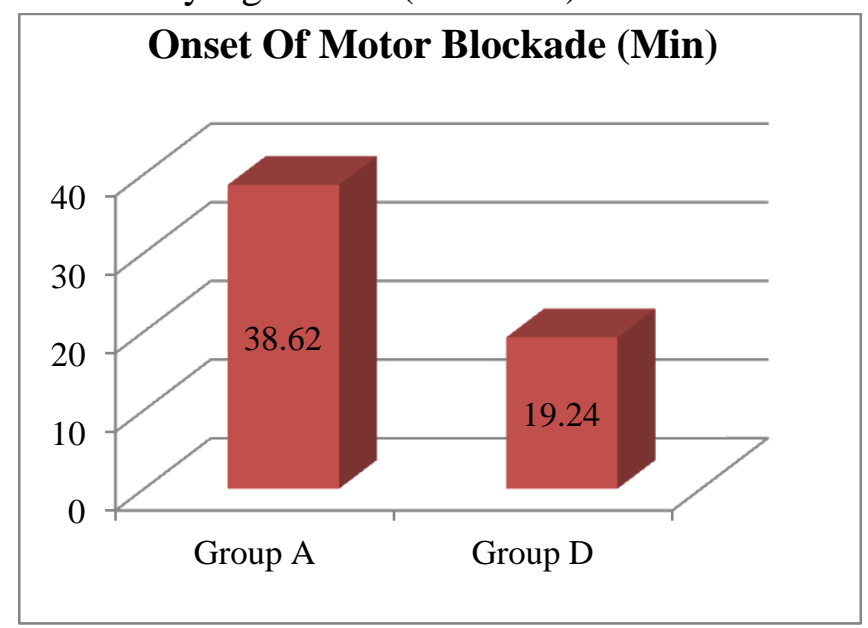

Figure 3: Onset of Motor Blockade (In Minutes) in studied cases.

Comparison of the duration of the sensory blockade in Group A and Group D revealed that the mean duration of sensory blockade in Group A and Group D was $418+/-102.24$ and $720+/$ 168.64 minutes respectively. The difference was found to be statistically highly significant.

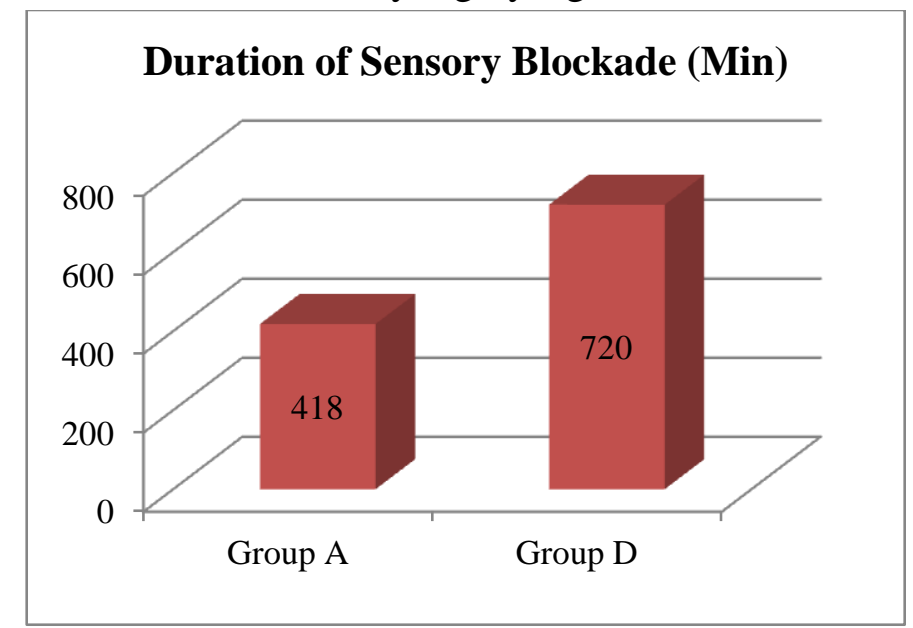

Figure 4: Mean Duration (In Minutes) of sensory blockade.

Comparison of the duration of the motor blockade in Group A and Group D revealed that the mean duration of motor blockade in Group A and Group D was $390+/-98.84$ and $580+/-154.32$ minutes respectively. The difference was found to be statistically highly significant.

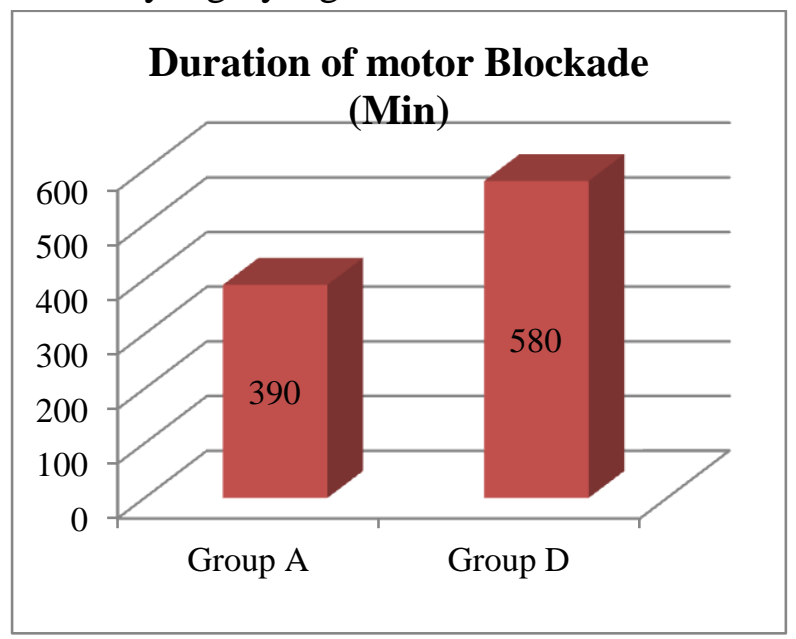

Figure 5: Mean Duration (In Minutes) of Motor blockade.

The comparison of duration of analgesia in both the cases revealed that there was a significant difference in duration of analgesia between these 2 groups. The duration of analgesia was significantly prolonged in group D $(792.84+/$ 184.24) as compared to Group A (398 +/- 94.42). The difference was found to be statistically significant. 


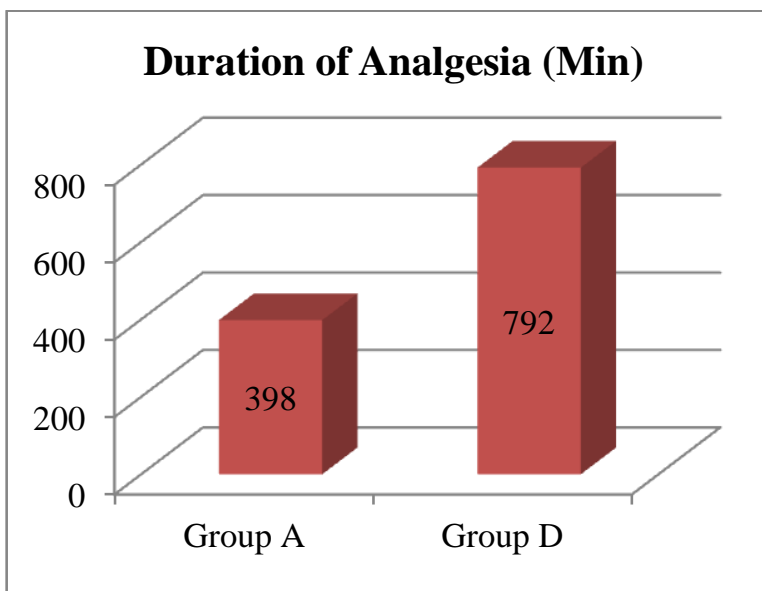

The analysis of sedation in both the groups (Group A and D ) revealed that up to 20 minutes the Ramsay sedation score in both the groups were comparable but after 20 minutes the patients in Group D had a higher sedation score at all the times till $1 \mathrm{hr}$ after competion of surgery. The difference was found to be statistically significant $(\mathrm{P}<0.01)$.

Figure 6 : Duration Of Analgesia (in Minutes) in studied cases

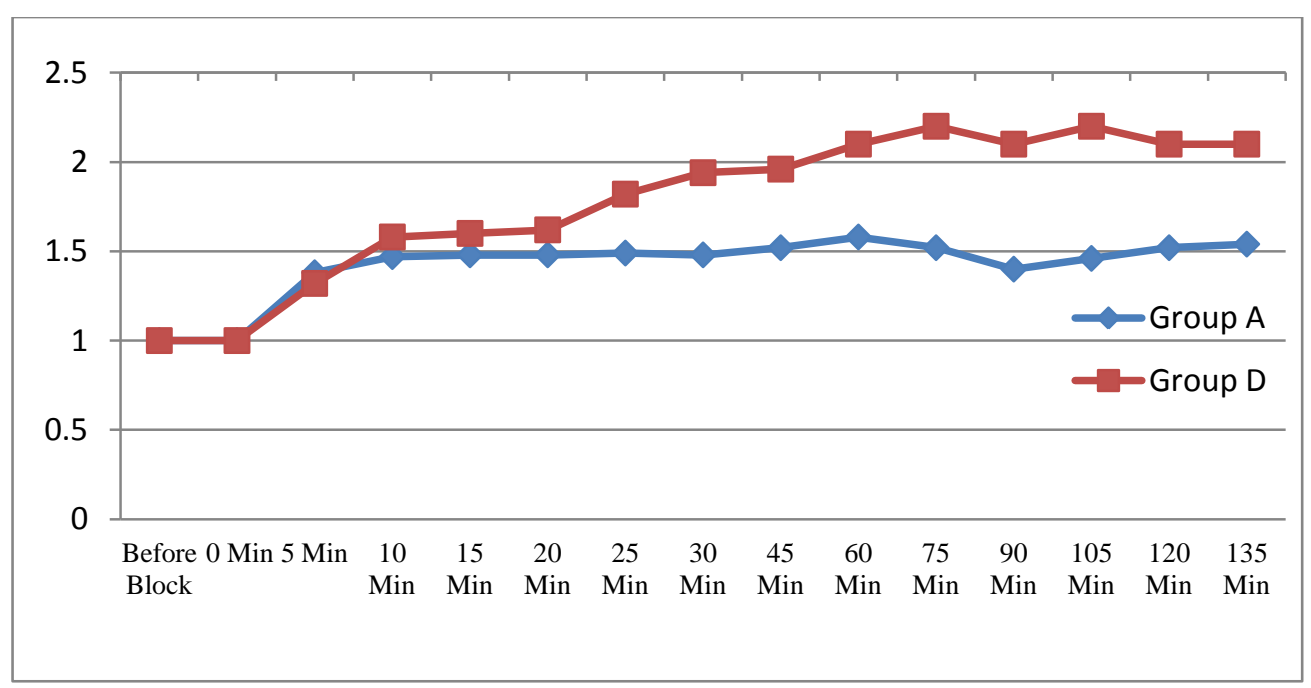

Figure 7: Comparison of Ramsay Sedation Score (RSS) during and till $1 \mathrm{I}$ hr postoperatively. The comparison of heart rates of the patients just before block, during surgery and up to 1 hour after surgery revealed that the mean heart rate in Group A was $78.86+/-10.20$ while in Group D the mean heart rate was found to be $76.88+/-10.20$. The difference was not statistically significant. However 2 patients developed bradycardia but didn't require any active intervention for it.

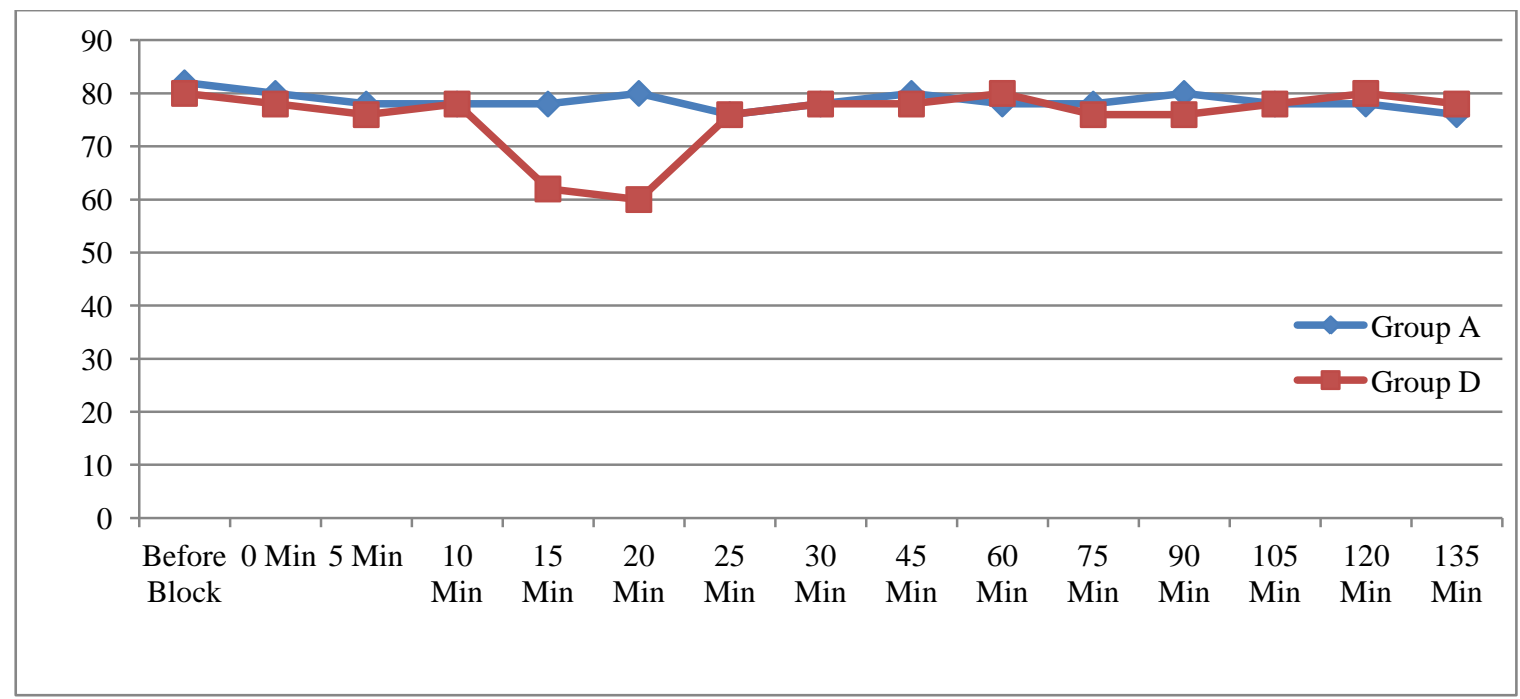

Figure 8: Comparison of heart rates in both the groups . 


\section{JMSCR Vol||05||Issue||11||Page 30494-30501||November}

The analysis of Mean Arterial pressure of both the groups revealed that MAP just before block, during surgery and up to 1 hour after surgery was comparable in both the groups and there was no statistically significant difference in MAP in both the groups.

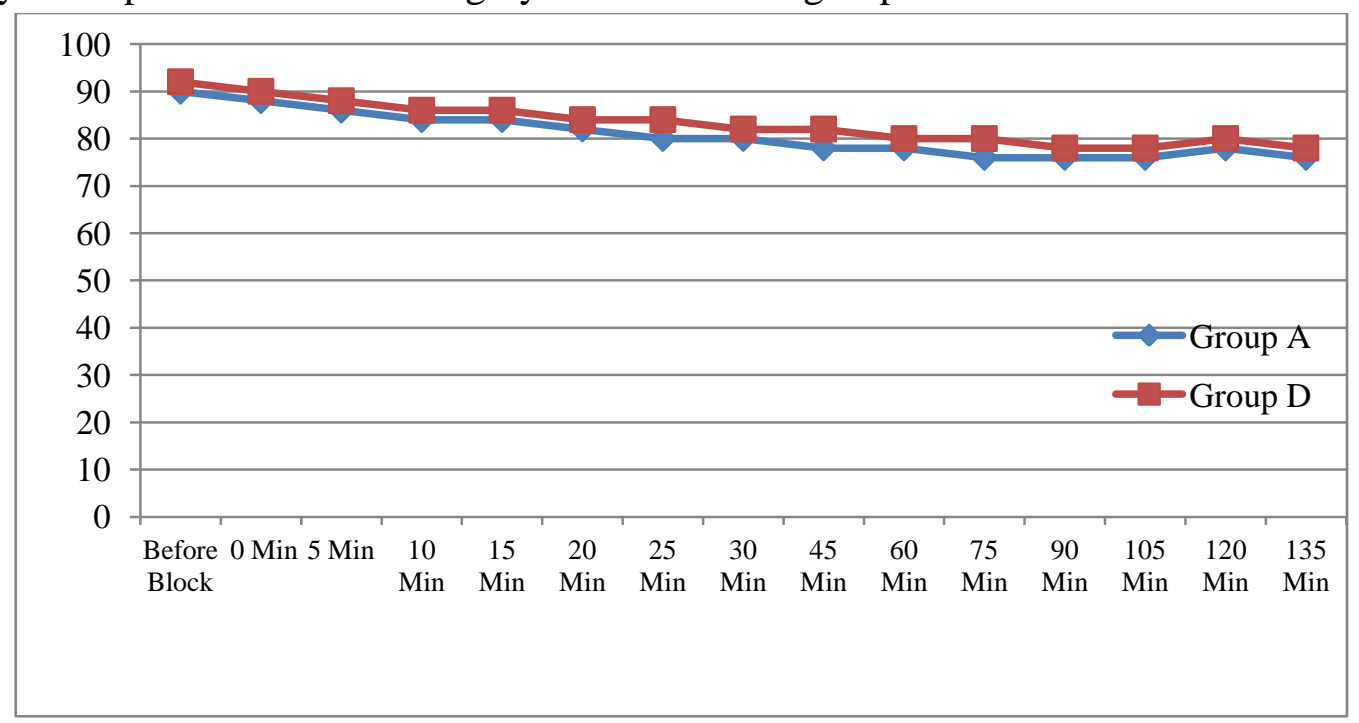

Figure 9: Comparison of Mean Arterial Pressure in both the groups.

The comparison of $\mathrm{SPO} 2$ in both the groups revealed that the $\mathrm{SPO} 2$ was maintained throughout the surgical procedure and in postoperative period in both the groups and there was no statistically significant difference in SPO2 of both the groups during or after surgery.

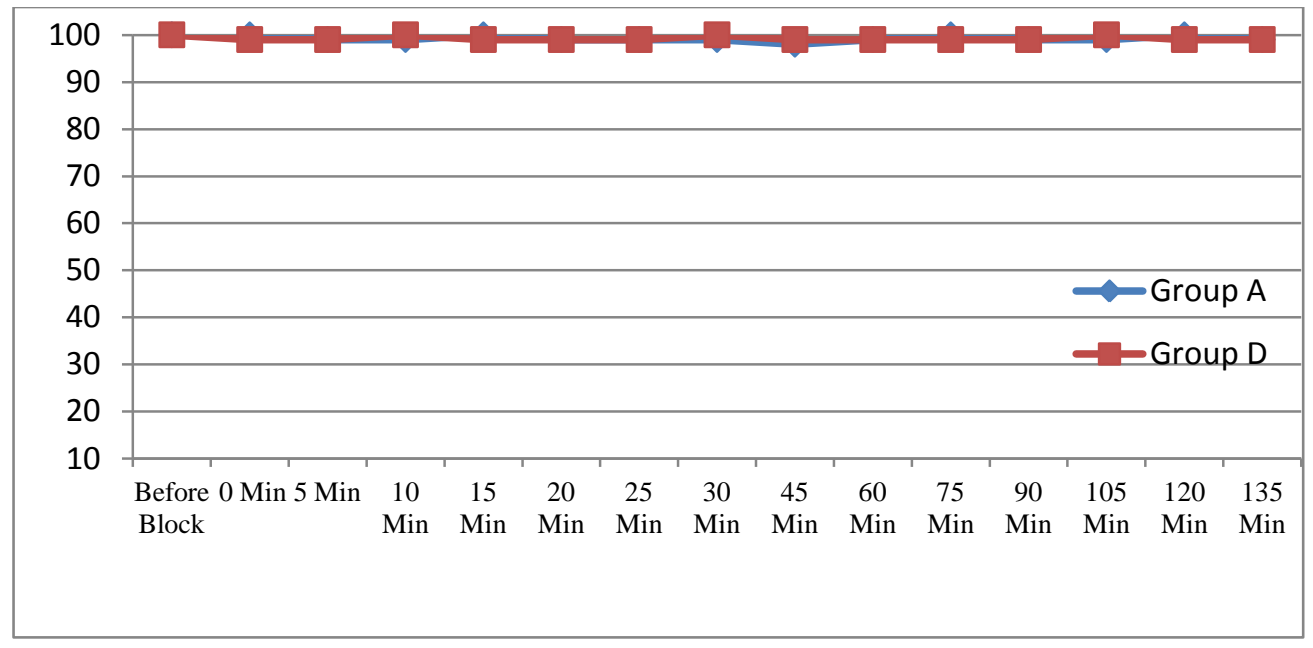

Figure 10: Comparison of SPO2 in both the groups .

\section{Discussion}

The proper selection of the local anesthetic agent and its concentration is a crucial step for surgeries under regional blocks. For upper limb surgeries under brachial plexus block long acting agents like bupivacaine and ropivacaine has been routinely used. Since Ropivacaine has a better safety profile and less incidence of side effects its use has been increased in recent years. Various adjuvants are being commonly used with ropivacaine to increase the analgesic during and in immediate postoperative period ${ }^{[10]}$. In this study we compared ropivacaine alone and ropivacaine with Dexmedetomidine which is an alpha-2 adrenergic receptor agonist. The findings of our prospective case control study showed that addition of Dexmedetomidine as an adjuvant with ropivacaine in supraclavicular brachial plexus block in upper limb surgeries has the effect of early onset and prolonged duration of sensory as well as motor blockade. The duration of analgesia was found to be statistically significantly better in 
patients in whom Dexmedetomidine was used as adjuvant (Group D).

In this study we found that the mean duration of surgery was $82+/-16.42$ and $76+/-14.32$ in group A and group D respectively. The difference was not found to be statistically significant. Similar findings were found in the studies conducted by Zhang Y and Marhofer et al ${ }^{[11,12]}$. The onset of sensory blockade was faster in group D than in Group A. Mean time for onset of sensory blockade was found to be $21.30+/-8.24$ in Group A while it was in 10.12 +/- 4.02 Group D. The difference was found to be statistically significant. Similarly onset of motor blockade was found to be earlier in group D than In group A. mean time for onset of motor blockade was found to be $38.62+/-14.28$ in Group A while it was in $19.24+/-5.86$ Group D. The difference was found to be statistically significant. Similarly the comparison of duration of sensory and motor blockades were found to be statistically significantly more in group D than in group A. Mean duration of sensory blockade in Group A and Group D was $418+/-102.24$ and 720 +/168.64 minutes respectively while mean duration of motor blockade in Group A and Group D was $390+/-98.84$ and $580+/-154.32$ minutes respectively. Similar conclusions were drawn in the studies conducted by Suneet Kathuria et al who found that onset of sensory as well as motor blockade was faster when Dexmedetomidine was used as an adjuvant with ropivacaine. Moreover they also found that the duration of sensory and motor blockade was more when Dexmedetomidine was used than in patients in whom only ropivacaine was used ${ }^{[13]}$.

The analysis of duration of analgesia in both the groups showed that the mean duration of analgesia in group D was $792.84+/-184.24$ minutes while in Group A this was $398+/-94.42$ minutes. The difference was found to be statistically significant. Similar findings were given by the study conducted by Jithendra et al who found that Dexmedetomidine when used as an adjuvant provides prolonged and better analgesia than ropivacaine alone ${ }^{[14]}$.

The quality of sedation was compared in both these groups on the basis of Ramsay sedation score. It was found that up to 20 minutes the Ramsay sedation score in both the groups were comparable but after 20 minutes the patients in Group D had a higher sedation score at all the times till $1 \mathrm{hr}$ after surgery. The difference was found to be statistically significant.

The analysis of vitals during and in immediate postoperative period revealed that the patients who received Dexmedetomidine were more likely to develop bradycardia than the patients who received ropivacaine only. But in our study this bradycardia didn't require any active intervention and resolved on its own. Nonetheless it must be kept in mind that Dexmedetomidine may cause bradycardia which may require active intervention. Similar findings were shown by the study conducted by Channabassappa et al who reported that addition of Dexmedetomidine was associated with bradycardia, hypotension and oxygen desaturation. Other vital parameters like mean arterial pressures and SPO2 were comparable in both the groups with no statistically significant difference ${ }^{[15]}$.

\section{Conclusion}

Our study concludes that use of Dexmedetomidine as an adjuvant with ropivacaine in supraclavicular brachial Plexus block in upper limb surgeries is associated with shortened onset and prolonged duration of sensory and motor blockade. Addition of Dexmedetomidine is associated with better analgesia and higher sedation. Anesthesiologists should remain vigilant for occurrence of bradycardia since higher chances of bradycardia is seen when Dexmedetomidine is used.

\section{Conflict of Interest: None.}

\section{References}

1. Smigovec E, Tripković B, Sulentić M, Smigovec I, Milavec D, Bukvić Mokos Z. 
Regional anesthesia for upper extremity surgery--our experience. Acta Dermatovenerol Croat. 2008;16(1):8-12.

2. Lewis SR, Price A, Walker KJ, McGrattan $\mathrm{K}$, Smith AF Ultrasound guidance for upper and lower limb blocks. Cochrane Database Syst Rev. 2015 Sep 11; (9):CD006459.

3. Jakobsson J, Johnson MZ. Perioperative regional anaesthesia and postoperative longer-term outcomes. F1000Research. 2016;5:F1000 Faculty Rev-2501.

4. Agarwal A, Kishore K. Complications And Controversies Of Regional Anaesthesia: A Review. Indian Journal of Anaesthesia. 2009;53(5):543-553.

5. Ali QE, Manjunatha L, Amir SH, Jamil S, Quadir A. Efficacy of clonidine as an adjuvant to ropivacaine in supraclavicular brachial plexus block: A prospective study. Indian Journal of Anaesthesia. 2014;58(6):709-713.

6. Ping Y, Ye Q, Wang W, Ye P, You Z. Dexmedetomidine as an adjuvant to local anesthetics in brachial plexus blocks: A meta-analysis of randomized controlled trials. Hanaoka. K, ed. Medicine. 2017;96(4):e5846.

7. Markham A, Faulds D. Ropivacaine : A Review of its Pharmacology and Therapeutic Use in Regional Anaesthesia. Drugs. 1996 Sep;52(3):429-449.

8. Kumar S, Palaria U, Sinha AK, Punera DC, Pandey V. Comparative evaluation of ropivacaine and ropivacaine with dexamethasone in supraclavicular brachial plexus block for postoperative analgesia. Anesthesia, Essays and Researches. 2014;8(2):202-208.

9. Hansen TG. Ropivacaine: a pharmacological review. Expert Rev Neurother. 2004 Sep;4(5):781-91

10. Rukewe A, Fatiregun A, Alonge TO. Orthopaedic anaesthesia for upper extremity procedures in a Nigerian hospital. Malawi Medical Journal.

2014;26(3):90-92.

11. Zhang Y, Wang CS, Shi JH, Sun B, Liu SJ, Li P, Li EY. Perineural administration of dexmedetomidine in combination with ropivacaine prolongs axillary brachial plexus block. Int J Clin Exp Med. 2014 Mar 15;7(3):680-5.

12. Marhofer D, Kettner SC, Marhofer P, Pils S, Weber $\mathrm{M}$, Zeitlinger $\mathrm{M}$. Dexmedetomidine as an adjuvant to ropivacaine prolongs peripheral nerve block: a volunteer study. $\mathrm{Br} \mathrm{J}$ Anaesth. 2013 Mar;110(3):438-42.

13. Kathuria S, Gupta S, Dhawan I. Dexmedetomidine as an adjuvant to ropivacaine in supraclavicular brachial plexus block. Saudi Journal of Anaesthesia. 2015;9(2):148-154.

14. Chinnappa J, Shivanna S, Pujari VS, Anandaswamy TC. Efficacy of dexmedetomidine with ropivacaine in supraclavicular brachial plexus block for upper limb surgeries. Journal of Anaesthesiology, Clinical Pharmacology. 2017;33(1):81-85.

15. Channabasappa SM, Shetty VR, Dharmappa SK, Sarma J. Efficacy and safety of dexmedetomidine as an additive to local anesthetics in peribulbar block for cataract surgery. Anesthesia, Essays and Researches. 2013;7(1):39-43. 